\title{
OnabotulinumtoxinA in the treatment of refractory chronic cluster headache
}

\author{
Christian Lampl ${ }^{1 *}$ (D), Mirjam Rudolph ${ }^{1}$ and Elisabeth Bräutigam²
}

\begin{abstract}
Background: Cluster headache $(\mathrm{CH})$ is a clinically well-defined primary headache disorder, approximately $20 \%$ of cluster headache sufferers experience recurrent attacks without periods of significant remission. For the treatment of chronic cluster headache $(\mathrm{CCH})$ only limited therapeutic options are available.

Methods: A potential refractory CCH patient group was identified according to the clinical definition of rCCH based on the consensus statement of the European Headache Federation (EHF). Treatment with OnabotulinumtoxinA (BoNT-A; Botox ${ }^{\oplus}, 150$ Allergan IU) was done according to the PREEMPT study protocol. A standardized headache diary was used for recording frequency, duration of attacks and pain intensity. To assess personal burden the HIT-6 and the Hospital Anxiety and Depression scale was used. Primary outcome measure was a $>50 \%$ reduction in headache minutes.
\end{abstract}

Results: Seventeen male patients suffering from rCCH, aged $32 \pm 11$ (mean \pm SD) years, presenting a mean disease duration of 6.6 years completed the study of 28 weeks. The cut-off point of $>50 \%$ reduction in headache minutes as positive result was reached in 58.8\%, 29.4\% experienced an improvement of 30-50\%. Mean frequency of headache days dropped from 28.2 to 11.8 days at week 24 ( $p=0.0001 ; 95 \% \mathrm{Cl}-21.33$ to -11.61 ;). Intensity of remaining attacks was also reduced significantly. Headache disability scores showed a trend to improvement after BoNT-A.

Conclusions: Encouraging results for the treatment with BoNT-A in rCCH patients were observed in our study population.

Keywords: Headache, Cluster headache, Refractoriness, Onabotulinumtoxin a, Prophylactic treatment

\section{Background}

Cluster headache $(\mathrm{CH})$ is a clinically well-defined primary headache disorder occurring in both episodic and chronic forms. Chronic cluster headache $(\mathrm{CCH})$ is a rare condition - approximately $20 \%$ of cluster headache sufferers experience recurrent attacks without periods of significant remission [1]. $\mathrm{CCH}$ may be unremitting from onset or evolve from episodic $\mathrm{CH}$ [2]. The evolution to $\mathrm{CCH}$ has been reported to occur in $3.8 \%$ to $12.9 \%$ of episodic $\mathrm{CH}$ sufferers [3]. According to the IHS classification ICHD-3rd version [4] $\mathrm{CCH}$ fulfils criteria for episodic cluster headache with attacks recurring without a remission period or with remissions lasting $<3$ month for at least one year. For the treatment of $\mathrm{CCH}$ only

\footnotetext{
* Correspondence: christian.lampl@ordensklinikum.at ${ }^{1}$ Headache Medical Center, Ordensklinikum Linz Barmherzige Schwestern, Linz, Austria

Full list of author information is available at the end of the article
}

limited therapeutic options are available so far. $\mathrm{CCH}$ sufferers often overuse symptomatic medications to treat $\mathrm{CH}$ attacks and may develop medication overuse headache $(\mathrm{MOH})$ in addition. To avoid this risk it is worth noting that the preventive treatment of $\mathrm{CCH}$ is essential. The decision about how to treat is largely based on clinical experience. For those with $\mathrm{CCH}$ preventive treatments are used for an indefinite period of time at least until the patient has been in remission without attacks for 6 months. It is often used in conjunction with a transitional agent and in combinations. Preventive medication should be preferably used as monotherapy but combinations of suggested preventive treatments are recommended especially if one preventive treatment decreases the attack frequency but does not control the situation satisfactorily, upon the physician's decision [5].

Botulinum Neurotoxin Type A (OnabotulinumtoxinA; BoNT-A) is well established in the treatment of chronic 
migraine (for review [6]). The intention of this study was to evaluate the efficacy and tolerability of BoNT-A as add-on therapy in refractory $\mathrm{CCH}(\mathrm{rCCH})$ patients.

\section{Methods}

Potential $\mathrm{rCCH}$ patients were identified from the database of our headache medical centre and from the registry of Linde Austria. The clinical definition of $\mathrm{rCCH}$ was based on the consensus statement of the European Headache Federation (EHF) [5]. This study was performed as an open label, non-randomised, single-centre study. Patients between 18 and 60 years of age were included. Exclusion criteria were those for BoNT-A therapy (e.g., generalised muscle weakness, myasthenia gravis, gravidity or known antibodies against botulinum toxin), symptomatic $\mathrm{CCH}$ and patients with occipital nerve stimulation (ONS) in situ. After a detailed elucidation of the procedure, injection sites, possible side effects and communication about the off label use of BoNT-A eligible patients undersigned informed consent. BoNT-A (Botox ${ }^{\circ}, 150$ Allergan IU) was used according to the Phase 3 REsearch Evaluating Migraine Prophylaxis Therapy (PREEMPT) [7, 8] study protocol (Fig. 1). A standardized headache diary was used including frequency (days/month), duration of attacks (min/attacks/day) and pain intensity (numeric rating scale, NRS). Pain duration was measured with a stop-watch (either commercial one or with mobile phone stop-watch). To assess personal burden patients were asked to fill out the six-item Headache Impact Test (HIT-6) and the Hospital Anxiety and Depression scale (HADS). The HIT 6 was designed to provide a global measure of adverse headache impact $[9,10]$ and was developed for use in screening and monitoring patients with headaches in both clinical practice and clinical research. The HADS [11] consists of two subscales: HADS-Anxiety (HADS-A) and
HADS-Depression (HADS-D) - each of seven items. In response to each item, participants report their subjective experience at the end of week 4 (baseline), week 12 and week 24 , rating it $0-3$ (3 indicating maximum symptom severity). The sum of each subscale has a potential range of $0-21$. As recommended in the original description [11] we took a threshold of 11 on the respective subscale to indicate caseness for anxiety or depression.

Observational period was 28 weeks, 4 weeks pre-treatment (baseline) and 24 weeks treatment phase. Headache frequency and duration was recorded per day and added at the end of each 4 weeks period (baseline; mean of each 4 weeks period at week 12 and mean of each 4 weeks period at week 24 of the treatment phase). 150 Allergan IU was injected in week 1 after baseline and in week 12. BoNT-A was given as add-on therapy, prior acute and prophylactic treatment was allowed to continue. Any change in medication was recorded. Mean and median values of baseline and week 24 were compared using Wilcoxon Signed Ranks tests and a statistically significant result set at the 95\% level $(p=0.05)$. Statistical Package for Social Studies (SPSS) version 17.0 (Aug 23, 2008) (SPSS Inc., Chicago, IL) was used to analyse our data. The study got approval by the local ethic committee (EK 4217; EudraCT No: 2017-003873-33). Primary endpoints were the change in headache days, change in headache minutes comparing baseline and week 24 , with a cut-off point of $50 \%$ or greater improvement. Secondary outcomes were achieving a 30\% to $50 \%$ improvement in headache minutes, change in pain intensity of the attacks, change in HIT6 and HADS scores and change in daily analgesics and prophylactic treatment.

\section{Results}

In total 27 patients (21 from the Linde data base, 6 from our headache center; f:m/5:16) were identified. Twentyone

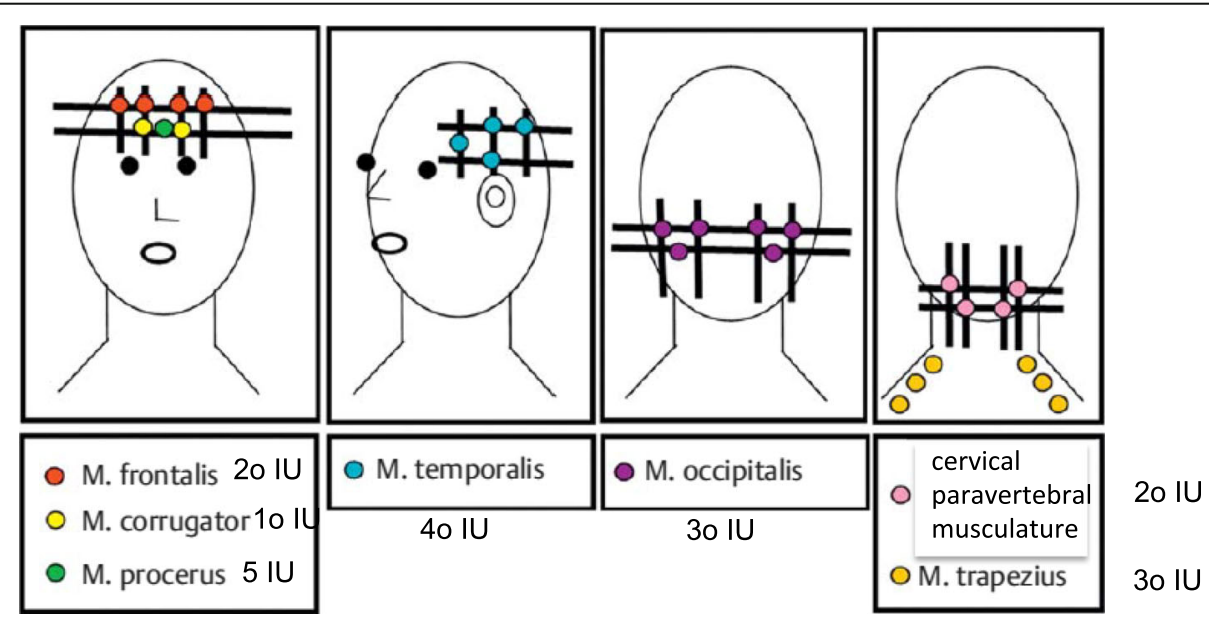

Fig. 1 Injection procedure of OnabotulinumtoxinA according to the PREEMPT study protocol 
patients were contacted, all of them agreed to participate. Due to the exclusion criteria 19 male patients with $\mathrm{rCCH}$, aged $32 \pm 11$ (mean $\pm \mathrm{SD}$ ) years, with a mean disease duration of 6.6 years were enrolled in the study and received initial treatment with BoNT-A. Two patients had to be excluded because of missing data according to the study protocol. Table 1 shows which treatment and which dose was tested before the patients were classified as $\mathrm{rCCH}$. The results of BoNT-A treatment are summarized in Table 2 . The cut-off point of $>50 \%$ as positive result was reached in $10 / 17$ patients $(58.8 \%)$. Three patients experienced total cessation of attacks within the study period; five patients (29.4\%) achieved a $30-50 \%$ reduction of attack minutes. In 2 patients no improvement was observed. Mean frequency of headache days dropped significantly to -16 days $(p=0.0001 ; 95 \% \mathrm{CI}-21.33$ to 11.61;). Mean headache minutes decreased to -1.329 ( $\mathrm{p}=$ $0.0001 ; 95 \%$ CI -1.778 .82 to -878.24$)$. Intensity of remaining attacks was also reduced significantly. The mean primary pain score at subjects' referral was $7.80 \pm$ 1.25. It dropped to a mean of $3.85 \pm 1.11$ ( $p=0.0038$; $95 \%$ CI -6.85 to -0.1 ). Percentage of pain score reduction did not correlate with the subjects' duration of illness (correlation coefficient $=0.113, p=0.756$ ). Headache disability scores showed a trend to improvement after BoNT-A (Table 3), HIT-6 showed a mean change of -12.7 points ( $p=0.021 ; 95 \%$ CI $-21,3$ to -1.8$)$, HADS-A a mean change of $-2.2(p=0.078 ; 95 \%$ CI -6.1 to -0.1$)$; HADS-D a mean change of $-3.2(p=0.063 ; 95 \% \mathrm{CI}-8.2$ to -0.1$)$. Adverse events were reported in 7 patients: Four observed an eyebrow ptosis, 3 patients mentioned a transient worsening in headache before improvement. All adverse events were rated as mild by patients and transient in nature. Preventive medication could be stopped in 6 patients (4 with topiramate, 2 with verapamil). In 4 patients dosage of verapamil could be bisected, 2 patients had no prophylactic treatment at baseline and 5 patients recorded no change in their prophylactic medication.

\section{Discussion}

BoNT-A was highly effective in $\mathrm{rCCH}$ in $10 / 17$ patients. Three "super-responders" were identified as well as a median reduction in headache minutes of $62 \%$ in all patients. Nine patients $(52.9 \%)$ reported a $>70 \%$ improvement in headache minutes. Clinically significant improvements were also seen in both HIT-6 and HADS scores. Our patients tried at least 3 preventive medications in recommended dosage and had suffered from $\mathrm{CCH}$ for a mean of 6.6 years at the time of BoNT-A treatment. This refractory nature of the group means that it is doubtful that our observations are due to spontaneous remission.

The efficacy of BoNT-A as $\mathrm{CCH}$ prophylaxis has so far been studied only in single case reports [12-14] and

Table 1 Demographic details, medication used to manage CCH before enrolment in the study

\begin{tabular}{|c|c|c|c|c|c|c|c|c|c|c|c|c|c|c|}
\hline \multirow[t]{2}{*}{ patients ID } & \multirow[t]{2}{*}{ triptans } & \multirow[t]{2}{*}{ oxygen } & \multirow[t]{2}{*}{$\begin{array}{l}\text { mid } \\
\text { analgesics }\end{array}$} & \multicolumn{2}{|c|}{$\begin{array}{l}\text { Verapamil } \\
(\mathrm{mg})\end{array}$} & \multicolumn{2}{|c|}{$\begin{array}{l}\text { Lithium } \\
(\mathrm{mg})^{*}\end{array}$} & \multicolumn{2}{|c|}{$\begin{array}{l}\text { Propranolol } \\
(\mathrm{mg})^{*}\end{array}$} & \multicolumn{2}{|c|}{$\begin{array}{l}\text { Amitriptyline } \\
(\mathrm{mg})^{*}\end{array}$} & \multicolumn{2}{|c|}{$\begin{array}{l}\text { Topiramate } \\
(\mathrm{mg})^{*}\end{array}$} & \multirow[t]{2}{*}{$\begin{array}{l}\text { Corticosteroids } \\
(\mathrm{mg})^{* *}\end{array}$} \\
\hline & & & & $\mathrm{hd}$ & ld & hd & ld & hd & ld & $\mathrm{hd}$ & Id & $\mathrm{hd}$ & Id & \\
\hline 1 & $\checkmark$ & 121 & $\checkmark$ & 480 & 480 & $x$ & $x$ & 120 & 80 & $x$ & $x$ & 200 & 200 & 25 \\
\hline 2 & $\checkmark$ & 151 & $\checkmark$ & 480 & 480 & 450 & $x$ & 120 & 80 & $?$ & 10 & 100 & 100 & $x$ \\
\hline 3 & $\checkmark$ & 151 & $\checkmark$ & 600 & 480 & 450 & $x$ & 120 & $x$ & $x$ & $x$ & 200 & 200 & $x$ \\
\hline 4 & $\checkmark$ & 151 & $\checkmark$ & 600 & 240 & $x$ & $x$ & 120 & $x$ & 75 & 75 & 100 & $x$ & $x$ \\
\hline 5 & $\checkmark$ & 121 & $\checkmark$ & 720 & 480 & $x$ & $x$ & 80 & 40 & $x$ & $x$ & 100 & $x$ & 75 \\
\hline 6 & $\checkmark$ & 121 & $\checkmark$ & 240 & 240 & 900 & 450 & 240 & $x$ & 25 & 25 & $x$ & $x$ & 10 \\
\hline 7 & $\checkmark$ & 121 & $\checkmark$ & 840 & 480 & $x$ & 240 & $x$ & $x$ & 10 & $x$ & 100 & 100 & 50 \\
\hline 8 & $\checkmark$ & 101 & $\checkmark$ & 480 & 480 & $x$ & $x$ & 40 & $x$ & $x$ & $x$ & 100 & 100 & $x$ \\
\hline 9 & $\checkmark$ & 121 & $\checkmark$ & 600 & $x$ & 450 & $x$ & 80 & $x$ & $?$ & $x$ & 100 & $x$ & 50 \\
\hline 10 & $\checkmark$ & $15 I$ & $\checkmark$ & 240 & 240 & 450 & $x$ & 120 & $x$ & 25 & $x$ & $x$ & $x$ & 50 \\
\hline 11 & $\checkmark$ & 151 & $\checkmark$ & 480 & 240 & 450 & 450 & $x$ & $x$ & $x$ & $x$ & 100 & 100 & $x$ \\
\hline 12 & $\checkmark$ & $15 I$ & $\checkmark$ & 480 & 480 & $x$ & $x$ & 120 & $x$ & $x$ & $x$ & 100 & 100 & 50 \\
\hline 13 & $\checkmark$ & $15 \mid$ & $\checkmark$ & 600 & 600 & $x$ & $x$ & 40 & $x$ & $x$ & $x$ & 200 & 200 & 25 \\
\hline 14 & $\checkmark$ & 151 & $\checkmark$ & 600 & $x$ & 450 & $x$ & $x$ & $x$ & $?$ & $x$ & 150 & $x$ & $x$ \\
\hline 15 & $\checkmark$ & 121 & $\checkmark$ & 600 & 480 & 450 & $x$ & $x$ & $x$ & $x$ & $x$ & 200 & 200 & $x$ \\
\hline 16 & $\checkmark$ & 151 & $\checkmark$ & 240 & 240 & 450 & 450 & $x$ & $x$ & $x$ & $x$ & 100 & 100 & 25 \\
\hline 17 & $\checkmark$ & 101 & $\checkmark$ & 720 & $x$ & 450 & $x$ & $?$ & $x$ & $x$ & $x$ & 200 & 200 & $x$ \\
\hline
\end{tabular}


Table 2 Demographic details, headache scores pre- and post- treatment with OnabotulinumtoxinA

\begin{tabular}{|c|c|c|c|c|c|c|c|c|c|}
\hline \multirow[t]{3}{*}{ patients ID } & \multirow[t]{3}{*}{ duration/y } & \multicolumn{2}{|l|}{ baseline } & \multicolumn{5}{|c|}{ treatment phase } & \multirow{3}{*}{$\begin{array}{l}\text { patient subjective } \\
\text { estimate of } \\
\text { response } \%{ }^{b}\end{array}$} \\
\hline & & \multirow{2}{*}{$\begin{array}{l}\text { frequency } \\
d / \text { mo }\end{array}$} & \multirow{2}{*}{$\begin{array}{l}\text { duration } \\
\text { min }\end{array}$} & \multicolumn{2}{|l|}{ week 12} & \multicolumn{2}{|l|}{ week 24} & \multirow[t]{2}{*}{ improvement $\%^{\mathrm{b}}$} & \\
\hline & & & & $\begin{array}{l}\text { frequency } \\
\mathrm{d} / \mathrm{mo}^{\mathrm{a}}\end{array}$ & $\begin{array}{l}\text { sum of } \\
\mathrm{min} / \text { bout }^{\mathrm{a}}\end{array}$ & $\begin{array}{l}\text { frequency } \\
d / m o^{a}\end{array}$ & $\begin{array}{l}\text { sum of } \\
\text { min bout }{ }^{a}\end{array}$ & & \\
\hline 1 & 7 & 30 & 2.250 & 17 & 1.755 & 14 & 1.320 & 41.3 & 50 \\
\hline 2 & 4 & 25 & 1.632 & 8 & 337 & 0 & 0 & 100 & $90-100$ \\
\hline 3 & 3 & 28 & 1.328 & 11 & 472 & 7 & 221 & 83.3 & $60-70$ \\
\hline 4 & 5 & 29 & 2.598 & 0 & 0 & 0 & 0 & 100 & 100 \\
\hline 5 & 5 & 30 & 3.148 & 12 & 1.065 & 8 & 531 & 83.1 & 75 \\
\hline 6 & 5 & 30 & 1.912 & 8 & 867 & 5 & 312 & 83,6 & 70 \\
\hline 7 & 9 & 28 & 2.491 & 12 & 1.289 & 7 & 1.333 & 46.4 & 50 \\
\hline 8 & 7 & 30 & 1.870 & 8 & 473 & 6 & 328 & 82.4 & $70-80$ \\
\hline 9 & 7 & 25 & 1.140 & 13 & 833 & 11 & 618 & 45.8 & 50 \\
\hline 10 & 4 & 27 & 3.456 & 14 & 2.855 & 12 & 1.565 & 54.7 & 50 \\
\hline 11 & 3 & 30 & 1.080 & 30 & 1.418 & 30 & 1.377 & 0 & 0 \\
\hline 12 & 3 & 30 & 3.020 & 16 & 1.844 & 14 & 813 & 73 & 50 \\
\hline 13 & 3 & 30 & 2.280 & 29 & 2.065 & 30 & 2.555 & 0 & 0 \\
\hline 14 & 6 & 28 & 1.680 & 0 & 0 & 0 & 0 & 100 & 100 \\
\hline 15 & 4 & 27 & 2.479 & 18 & 1.349 & 22 & 1.662 & 32,9 & $20-30$ \\
\hline 16 & 2 & 30 & 3.040 & 17 & 1.364 & 14 & 839 & 72.4 & $50-70$ \\
\hline 17 & 5 & 23 & 1.855 & 21 & 989 & 20 & 1.200 & 35,3 & 20 \\
\hline Mean & 5 & 28.2 & 2.192 & 13.8 & 1.117 & 11.8 & 863 & 62 & \\
\hline median & 5 & 29 & 2.250 & 13.5 & 1.065 & 11 & 813 & 62 & \\
\hline (range) & $(2-9)$ & $(23-30)$ & $(1.080-3.148)$ & $(0-30)$ & $(0-2.855)$ & $(0-30)$ & $(0-2.555)$ & $(0-100)$ & \\
\hline
\end{tabular}

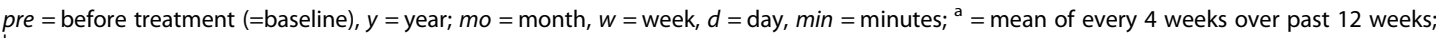

$\mathrm{b}=$ baseline vs week 24

in one open trial with a group of $12 \mathrm{CH}$ patients following a standardised injection scheme [15], but not the PREEMPT study protocol. Using 50 IU of BoNT-A the German study group observed a reduction of attack frequency in $25 \%(3 / 12)$ of all study patients and in $33 \%$ (3/9) of patients with $\mathrm{CCH}$. Interestingly they observed a better approach in the majority of patients who suffered from $\mathrm{CCH}$ for a shorter period (1.5-2 years) than patients with a longer duration of $\mathrm{CCH}$ (3-12 years). That could not be observed in our study population. Although the aetiology and pathophysiology of $\mathrm{CH}$ is still not completely understood we do have evidence from PET studies [16, 17], voxel-based morphometry [18] and stereotactic hypothalamic deep brain stimulation $[19,20]$, that a dysfunction of the ipsilateral posterior hypothalamus may cause a secondary activation of the trigemino-autonomic brainstem pathways [21]. This activation leads to the release of calcitonin gene-related peptide (CGRP) a potent vasodilator and neurotransmitter [22]. The activation of the trigeminal system during $\mathrm{CH}$ attack is indicated by the elevation of CGRP plasma levels in the external jugular vein [23]. CGRP plasma levels are also elevated interictally in episodic $\mathrm{CH}$ patients in the bout compared to outside the bout [23]. The question now is how BoNT-A interferes with the pathophysiology of $\mathrm{CCH}$ and whether it is responsible for the positive effects observed in our study. BoNT-A inhibits the release of CGRP from peripheral trigeminal neurons and consequently reduces the CGRP-mediated trigeminal sensitization in migraine $[24,25]$. Furthermore, it was suggested that BoNT-A exhibits its actions in pain and migraine by reaching dural trigeminal afferents [26, 27]. Due to the ability of BoNT-A to undergo retrograde axonal transport to the CNS [28] neurotransmitters like Substance P [29] or CGRP [30] might be modulated not only locally at the injection site but also at anatomically connected sites in the trigeminal terminals.

The effects of BoNT-A in the cranial dura could be reconstructed as follows [31]: after peripheral injection BoNT-A is taken up by sensory nerve endings and axonally transported to trigeminal ganglion. After transcytosis the toxin reaches dural nerve endings containing CGRP, suppresses the CGRP-mediated sensitization of the trigeminovascular system, resulting 
Table 3 Headache-associated disability scores pre- and post- treatment with OnabotulinumtoxinA

\begin{tabular}{|c|c|c|c|c|c|c|c|c|c|}
\hline \multirow[b]{2}{*}{ patients ID } & \multicolumn{3}{|c|}{ HIT- 6 (36-76) } & \multicolumn{3}{|c|}{ HADS - A (0-21) } & \multicolumn{3}{|c|}{ HADS - D (0-21) } \\
\hline & pre & w 24 & change in score & pre & w 24 & change in score & pre & w 24 & change in score \\
\hline 1 & 70 & 50 & 20 & 18 & 15 & 3 & 8 & 6 & 2 \\
\hline 2 & 58 & 36 & 22 & 15 & 9 & 6 & 12 & 8 & 4 \\
\hline 3 & 67 & 47 & 20 & 17 & 15 & 2 & 15 & 12 & 3 \\
\hline 4 & 76 & 42 & 34 & 15 & 6 & 9 & 6 & 3 & 3 \\
\hline 5 & 78 & 58 & 20 & 15 & 12 & 3 & 9 & 4 & 5 \\
\hline 6 & 58 & 52 & 6 & 11 & 8 & 3 & 10 & 3 & 7 \\
\hline 7 & 63 & 58 & 5 & 13 & 11 & 2 & 10 & 7 & 3 \\
\hline 8 & 63 & 42 & 21 & 13 & 12 & 1 & 8 & 2 & 6 \\
\hline 9 & 57 & 42 & 13 & 12 & 11 & 1 & 12 & 11 & 1 \\
\hline 10 & 78 & 68 & 10 & 11 & 12 & -1 & 11 & 9 & 2 \\
\hline 11 & 65 & 68 & -3 & 13 & 15 & -2 & 14 & 15 & -1 \\
\hline 12 & 68 & 57 & 11 & 11 & 12 & -1 & 11 & 5 & 6 \\
\hline 13 & 65 & 65 & 0 & 18 & 21 & -3 & 16 & 16 & 0 \\
\hline 14 & 56 & 36 & 20 & 12 & 6 & 6 & 4 & 0 & 4 \\
\hline 15 & 53 & 57 & -4 & 14 & 12 & 2 & 15 & 12 & 3 \\
\hline 16 & 68 & 54 & 14 & 14 & 9 & 5 & 12 & 9 & 3 \\
\hline 17 & 76 & 72 & 4 & 12 & 11 & 1 & 14 & 11 & 3 \\
\hline Mean $(95 \% \mathrm{Cl})$ & 65.8 & 53.1 & $-12.7(-21.3 ;-1.8)$ & 13.8 & 11.6 & $-2.2(-6.1 ;-0.1)$ & 11.0 & 7.8 & $-3.2(-8.2 ;-0.1)$ \\
\hline median (range) & $65(53-78)$ & $54(36-72)$ & $13(-3-34)$ & $13(11-18)$ & $12(6-21)$ & $2(-2-9)$ & $11(6-16)$ & $8(0-16)$ & $3(-1-7)$ \\
\hline
\end{tabular}

pre = before treatment (=baseline), $w=$ week; HIT-6 = Headache Impact Test, HADS=Hospital Anxiety and Depression Scale, $A=$ anxiety, $D=\operatorname{depression}$

in reduction in local neurogenic inflammation. At present this seems to be the most convincing hypothesis of the action of BoNT-A in migraine and $\mathrm{CH}$. Moreover modulation of neurotransmitter release at higher order neurons could contribute to pain attenuation as brain Gamma-aminobutyric acid (GABA) concentration may be correlated to migraine intensity [32]. This could also be a mechanism in cluster headache patients to modulate pain intensity.

Although we observed encouraging results for the treatment with BoNT-A in $\mathrm{rCCH}$ patients, major limitations of this study arise from its open design and the small patient number. Previous studies of BoNT-A have also reported a significant placebo response; therefore we cannot exclude this as a potential confounding factor in our outcomes as well as effects of concomitant preventive therapy. However, the good response rates and consistent efficacy of repeated BoNT-A application in our study population with an extraordinary pain condition suggest that the response to BoNT-A in this series entirely cannot be attributed to a placebo response. Further multicentre studies with higher patient numbers will be needed to further clarify if BoNT-A is effective in the prophylactic treatment of $\mathrm{rCCH}$. As the syndrome is quite rare, it is still essential to collect and publish large case series regarding clinical manifestations and treatment options.

\section{Conclusions}

Our data suggest that the injection of BoNT-A could be beneficial as add-on therapy in patients with otherwise $\mathrm{rCCH}$. However, these preliminary results has to be confirmed in double-blind, randomised, controlled studies. Especially patient characteristics that predict benefit from BoNT-A treatment should be identified. In our experience it is essential to use the PREEMPT study protocol for the injection procedure.

\section{Abbreviations}

BoNT-A: OnabotulinumtoxinA; CCH: Chronic Cluster Headache; CGRP: Calcitonin gene-related peptide; CH: Cluster Headache; GABA: Gamma-aminobutyric acid; HADS: Hospital Anxiety and Depression scale; HIT-6: Headache Impact Test; ICHD: International Classification of Headache Disorders; IU: International Units; $\mathrm{MOH}$ : Medication Overuse Headache; NRS: Numeric Rating Scale; PREEMPT: Phase 3 REsearch Evaluating Migraine Prophylaxis Therapy -; rCCH: Refractory Chronic Cluster Headache; SPSS: Statistical Package for Social Studies

\section{Availability of data and materials}

The dataset supporting the conclusions of this article is included within the article and its additional files.

\section{Authors' contributions}

$\mathrm{CL}$ and MR conceived the idea for this analysis, made possible by the design of the original questionnaire, which had been led by $C L$ and MR. Both contributed to data acquisition. CL, MR and EB performed analysis and data interpretation. $C L$ drafted the article with input from MR and EB. All authors reviewed and approved the final manuscript. 


\section{Authors' information}

No relevant information about the authors that may aid the reader's interpretation of the article, and understand the standpoint of the authors.

\section{Ethics approval and consent to participate}

The study was approved by the local ethic committee of the Ordensklinikum Linz Barmherzige Schwestern (EK Number 4217).

All patients undersigned informed consent.

\section{Competing interests}

The authors declare that they have no competing interests.

\section{Publisher's Note}

Springer Nature remains neutral with regard to jurisdictional claims in published maps and institutional affiliations.

\section{Author details}

'Headache Medical Center, Ordensklinikum Linz Barmherzige Schwestern, Linz, Austria. ${ }^{2}$ Headache Medical Center, Department of Radio-Oncology, Ordensklinikum Linz Barmherzige Schwestern, Linz, Austria.

Received: 19 April 2018 Accepted: 13 June 2018

Published online: 19 June 2018

\section{References}

1. Bahra A, May A, Goadsby PJ (2002) Cluster headache: a prospective clinical study with diagnostic implications. Neurology 58:354-361

2. Pearce JM (1993) Natural history of cluster headache. Headache 33:235-236

3. Manzoni GC, Micieli G, Granella F, Tassorelli C, Zanferrari C, Cavallini A (1991) 189 patients. Cephalalgia 11:169-174

4. Headache Classification Committee of the International Headache Society (IHS) (2018) The international classification of headache disorders, 3rd edition. Cephalalgia 38:1-211

5. Mitsikostas DD, Edvinsson L, Jensen RH, Katsarava Z, Lampl C, Negro A, Osipova V, Paemeleire K, Siva A, Valade D, Martelletti P (2014) Refractory chronic cluster headache: a consensus statement on clinical definition from the European headache federation. J Headache Pain 27(15):79

6. Frampton JE, Silberstein S (2018) OnabotulinumtoxinA: a review in the prevention of chronic migraine. Drugs 78:589-600

7. Aurora SK, Dodick DW, Turkel CC, RE DG, Silberstein SD, Lipton RB, Diener HC, Brin MF (2010) PREEMPT 1 Chronic Migraine Study Group (2010) Onabotulinumtoxin a for treatment of chronic migraine: results from the double-blind, randomized, placebo-controlled phase of the PREEMPT 1 trial. Cephalalgia 30:793-803

8. Diener HC, Dodick DW, Aurora SK, Turkel CC, RE DG, Lipton RB, Silberstein SD, Brin MF (2010) PREEMPT 2 Chronic Migraine Study Group (2010) Onabotulinumtoxin a for treatment of chronic migraine: results from the double-blind, randomized, placebo-controlled phase of the PREEMPT 2 trial. Cephalalgia 30:804-814

9. Ware JE Jr, Bjorner JB, Kosinski M (2000) Practical implications of item response theory and computerized adaptive testing: a brief summary of ongoing studies of widely used headache impact scales. Med Care 38: 73-82

10. Kosinski M, Bayliss MS, Bjorner JB, Ware JE Jr, Garber WH, Batenhorst A, Cady R, Dahlöf CG, Dowson A, Tepper S (2003) A six-item short-form survey for measuring headache impact: the HIT-6. Qual Life Res 12:963-974

11. Zigmond AS, Snaith RP (1983) The hospital anxiety and depression scale. Acta Psychiatr Scand 67:361-370

12. Robbins L (2001) Botulinum toxin a (Botox) for cluster headache: 6 cases. Cephalalgia 21:499-500

13. Freund BJ, Schwartz M (2000) The use of botulinum toxin-a in the treatment of refractory cluster headache: case reports. Cephalalgia 20: $325-331$

14. Smuts JA, Barnard PWA (2000) Botulinum toxin type a in the treatment of headache syndromes: a clinical report on 79 patients. Cephalalgia 20:332

15. Sostak P, Krause P, Förderreuther S, Reinisch V, Straube A (2007) Botulinum toxin type-a therapy in cluster headache: an open study. J Headache Pain 8: 236-241

16. Sprenger T, Valet M, Hammes M, Erhard P, Berthele A, Conrad B, Tolle TR (2004) Hypothalamic activation in trigeminal autonomic cephalgia: functional imaging of an atypical case. Cephalalgia 24:753-757
17. May A, Bahra A, Buchel C, Frackowiak RS, Goadsby PJ (1998) Hypothalamic activation in cluster headache attacks. Lancet 352:275-278

18. Hardebo JE (1994) How cluster headache is explained as an intracavernous inflammatory process lesioning sympathetic fibers. Headache 34:125-131

19. Franzini A, Ferroli P, Leone M, Broggi G (2003) Stimulation of the posterior hypothalamus for treatment of chronic intractable cluster headaches: first reported series. Neurosurgery 52:1095-1099

20. Leone M, Franzini A, Broggi G, Bussone G (2003) Hypothalamic deep brain stimulation for intractable chronic cluster headache: a 3-year followup. Neurol Sci 24(2):143-145

21. Malick A, Strassman RM, Burstein R (2000) Trigeminohypothalamic and reticulohypothalamic tract neurons in the upper cervical spinal cord and caudal medulla of the rat. J Neurophysiol 84:2078-2112

22. Zagami AS, Goadsby PJ, Edvinsson L (1990) Stimulation of the superior sagittal sinus in the cat causes release of vasoactive peptides. Neuropeptides 16:69-75

23. Goadsby PJ, Edvinsson L (1994) Human in vivo evidence for trigeminovascular activation in cluster headache. Neuropeptide changes and effects of acute attacks therapies. Brain 117:427-434

24. Fanciullacci M, Alessandri M, Sicuteri R, Marabini S (1997) Responsiveness of the trigeminovascular system to nitroglycerine in cluster headache patients. Brain 120:283-288

25. Cernuda-Morollón E, Martínez-Camblor P, Ramón C, Larrosa D, SerranoPertierra E, Pascual J (2014) CGRP and VIP levels as predictors of efficacy of onabotulinumtoxin type a in chronic migraine. Headache 54:987-995

26. Matak I, Lacković Z (2014) Botulinum toxin a, brain and pain. Prog Neurobiol 119-120:39-59

27. Ramachandran R, Yaksh TL (2014) Therapeutic use of botulinum toxin in migraine: mechanisms of action. Br J Pharmacol 171:4177-4192

28. Huang P, Khan I, Suhail M, Malkmus S, Yaksh T (2011) Spinal botulinum neurotoxin B: effects on afferent transmitter release and nociceptive processing. PLoS One 6:e19126

29. Chien C, Lee H, Wu C, Li P (2012) Inhibitory effect of botulinum toxin type a on the NANC system in rat respiratory models of neurogenic inflammation. Arch Biochem Biophys 524:106-113

30. Hou YP, Zhang YP, Song YF, Zhu CM, Wang YC, Xie GL (2007) Botulinum toxin type a inhibits rat pyloric myoelectrical activity and substance $P$ release in vivo. Can J Physiol Pharmacol 85:209-214

31. Lacković Z, Filipović B, Matak I, Helyes Z (2016) Activity of botulinum toxin type a in cranial dura: implications for treatment of migraine and other headaches. Br J Pharmacol 173:279-291

32. Wiegand H, Erdmann G, Wellhoner HH (1976) 125I-labelled botulinum a neurotoxin: pharmacokinetics in cats after intramuscular injection. Naunyn Schmiedeberg's Arch Pharmacol 292:161-165

\section{Submit your manuscript to a SpringerOpen ${ }^{\circ}$ journal and benefit from:}

- Convenient online submission

- Rigorous peer review

- Open access: articles freely available online

- High visibility within the field

Retaining the copyright to your article

Submit your next manuscript at $>$ springeropen.com 